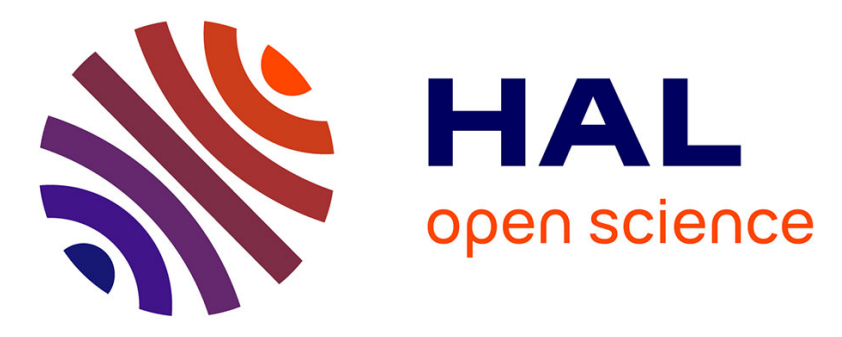

\title{
Pathological lesions in colonic biopsies during Parkinson's disease.
}

Thibaud Lebouvier, Tanguy Chaumette, Philippe Damier, Emmanuel Coron, Yann Touchefeu, Sylvie Vrignaud, Philippe Naveilhan, Jean-Paul Galmiche, Stanislas Bruley Des Varannes, Pascal Derkinderen, et al.

\section{To cite this version:}

Thibaud Lebouvier, Tanguy Chaumette, Philippe Damier, Emmanuel Coron, Yann Touchefeu, et al.. Pathological lesions in colonic biopsies during Parkinson's disease.. Gut, 2008, 57 (12), pp.1741-3. 10.1136/gut.2008.162503 . inserm-00342056

\section{HAL Id: inserm-00342056 https://www.hal.inserm.fr/inserm-00342056}

Submitted on 26 Nov 2008

HAL is a multi-disciplinary open access archive for the deposit and dissemination of scientific research documents, whether they are published or not. The documents may come from teaching and research institutions in France or abroad, or from public or private research centers.
L'archive ouverte pluridisciplinaire $\mathbf{H A L}$, est destinée au dépôt et à la diffusion de documents scientifiques de niveau recherche, publiés ou non, émanant des établissements d'enseignement et de recherche français ou étrangers, des laboratoires publics ou privés. 


\section{Pathological lesions in colonic biopsies during Parkinson's disease}

T Lebouvier, T Chaumette, $\mathrm{P}$ Damier, E Coron, Y Touchefeu, S Vrignaud, P Naveilhan, J-P Galmiche, S Bruley des Varannes, P Derkinderen and M Neunlist

Gut 2008;57;1741-1743

doi:10.1136/gut.2008.162503

Updated information and services can be found at:

http://gut.bmj.com/cgi/content/full/57/12/1741

These include:

References This article cites 6 articles, 1 of which can be accessed free at: http://gut.bmj.com/cgi/content/full/57/12/1741\#BIBL

Email alerting Receive free email alerts when new articles cite this article - sign up in the box at service the top right corner of the article

Notes

To order reprints of this article go to:

http://journals.bmj.com/cgi/reprintform

To subscribe to Gut go to:

http:/journals.bmj.com/subscriptions/ 

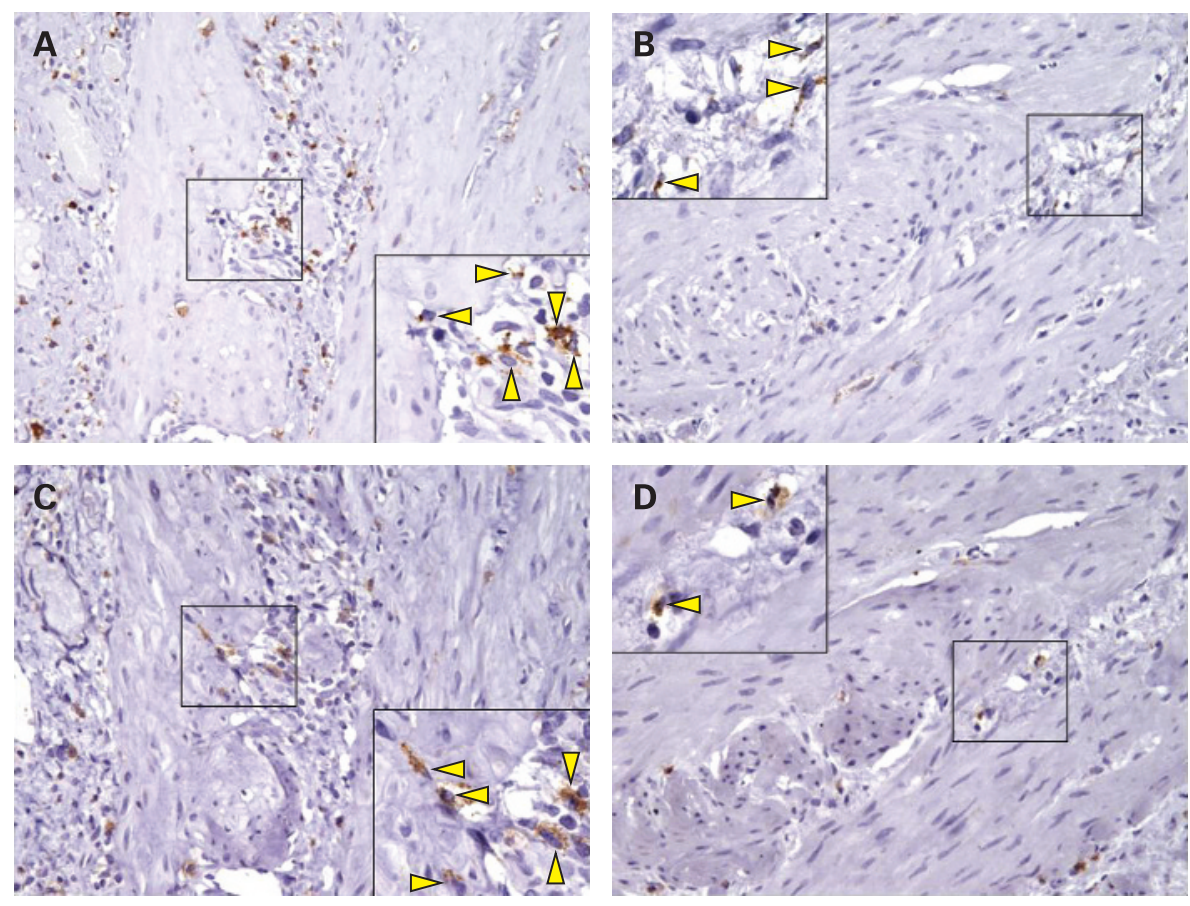

Figure 1 Immunohistochemistry for CD68 and cyclooxygenase-2 (COX-2) in muscularis macrophages. CD68 positive cells, were quite evenly distributed in muscle layer of the gallbladder in placebo-treated gallstones patients $(A)$ and were scarcely present in gallbladder of ursodeoxycholic acid (UDCA)-treated patients (B). A similar pattern was exhibited by COX-2 positive cells, in muscle layer of gallbladder in placebo-treated patients (C) and UDCA-treated patients (D). A/C, B/D refer to the same patient. The figure shows corresponding fields for each patient. Original magnification, $\times 200$. High power field, $\times 400$.

(Sanofi-Winthrop, Riells y Viabrea, Spain) for 30 days. Criteria for eligibility, randomisation of patients and blinding were those used in our previous randomised study. ${ }^{1}$ Following laparoscopic cholecystectomy, GB specimens were collected for routine histology and immunohistochemisty, the latter performed by the streptavidin-biotin method. Mouse monoclonal antibodies against COX-2 protein (clone CX-294; Dako, Glostrup, Denmark) and mouse monoclonal antibodies against CD68 (clone M7103; Dako) were used. Part of the GB tissue was collected for muscle cell contraction to cholecystokinin 8 (CCK-8) studies as well as for measurement of prostaglandin (PG) E2 levels as described elsewhere. ${ }^{1}$

Following randomisation, eight patients received UDCA and 11 received placebo, for 30 days. Staining with haematoxylin \& eosin revealed chronic cholecystitis, with mild inflammatory infiltrates, in all GBs with gallstones, treated with UDCA or placebo. No histopathological lesions were

Table 1 Mean number (with SD in parentheses) of positively stained cells in 10 consecutive microscopic fields

\begin{tabular}{llll}
\hline & Controls & Placebo & UDCA \\
\hline CD68 & $11.9(8.1)$ & $36.2(11)^{*}$ & $19.6(6)^{* *}$ \\
COX-2 & $10.5(6.8)$ & $30.6(12)^{*}$ & $15.2(5.5)^{* *}$ \\
\hline
\end{tabular}

${ }^{*} \mathrm{p}<0.001$ vs controls; ${ }^{* *} \mathrm{p}<0.01$ vs placebo.

COX-2, cyclooxygenase-2; UDCA, ursodeoxycholic acid. observed in GBs from a control group, represented by 10 alithiasic GBs removed from patients with neoplastic diseases not involving the GB. The number of CD68 positive macrophages in the muscle layer of GBs from gallstone patients was significantly higher compared to that in control patients. In UDCA-treated patients, the number of CD68 positive macrophages, in GB muscle, was significantly lower when compared to that in placebo-treated patients. Positive COX-2 expression was almost exclusively present in macrophages within the muscle layer (fig 1). The number of COX-2 positive cells was higher in muscle from symptomatic gallstone patients compared to controls and, likewise macrophages, significantly lower following UDCA treatment (table 1, fig 1). A direct and significant correlation was observed between positivity for CD68 and COX-2 (Spearman's $\rho=0.7, p<0.01$ ). As in our previous study, the production of PGE2 was significantly lower, following UDCA than after placebo. Furthermore, muscle contraction, induced by increasing concentrations of CCK-8 (assessed in four patients in each group) was significantly higher in the UDCA, compared to placebo, group (maximal contraction to CCK-8 $10^{-8} \mathrm{~mol} / 1$ was 25.1 (SD 3) vs 12 (SD 4)\%, respectively; $\mathrm{p}<0.001)$. Our more recent data show that an inflammatory macrophage infiltrate is present in the GB muscle layer of cholesterol gallstone patients. UDCA decreases the presence of macrophages in the muscle layer and confirms improvement in GB muscle cell contraction. These results suggest that activated macrophages play a role in muscle cell dysfunction and add insight into the anti-inflammatory action of UDCA, which may explain some of the therapeutic effects of this bile acid in liver diseases as well as other gastrointestinal inflammatory conditions.

\section{P L Guarino, ${ }^{1}$ S Carotti, ${ }^{2}$ S Morini, ${ }^{2}$ G Perrone, ${ }^{3}$ J Behar, ${ }^{4}$ A Altomare, ${ }^{1}$ R Alloni, ${ }^{1}$ R Caviglia, S Emerenziani, ${ }^{1}$ C Rabitti, ${ }^{3}$ M Cicala ${ }^{1}$}

${ }^{1}$ Department of Digestive Diseases, Campus Bio-Medico University, Rome, Italy; ${ }^{2}$ Department of Biomedical Research, Campus Bio-Medico University, Rome, Italy: ${ }^{3}$ Surgical Pathology, Campus Bio-Medico University, Rome, Italy; ${ }^{4}$ Rhode Island Hospital and Brown University Medical School, Providence, Rhode Island, USA

Correspondence to: Dr M P L Guarino, Dipartimento di Malattie dell'Apparato Digerente, Università Campus BioMedico, Via Alvaro del Portillo, 21-00128 Rome, Italy; m.guarino@unicampus.it

\section{Competing interests: None.}

Ethics approval: This study was approved by the Ethics Committee of Campus Bio-Medico University on 21 June 2001.

Gut 2008;57:1740-1741. doi:10.1136/gut.2008.160333

\section{REFERENCES}

1. Guarino MP, Cong P, Cicala M, et al. Ursodeoxycholic acid improves muscle contractility and inflammation in symptomatic gallbladders with cholesterol gallstones. Gut 2007;56:815-20.

2. Ljubuncic $\mathbf{P}$, Fuhrman B, Oiknine J, et al. Effect of deoxycholic acid and ursodeoxycholic acid on lipid peroxidation in cultured macrophages. Gut 1996:39:475-8.

3. Iwaki T, Ishizaki K, Kinoshita S, et al. Protective effects of ursodeoxycholic acid on chenodeoxycholic acid-induced liver injury in hamsters. World J Gastroenterol 2007;13:5003-8.

4. Wehner S, Behrendt FF, Lyutenski BN, et al. Inhibition of macrophage function prevents intestinal inflammation and postoperative ileus in rodents. Gut 2007;56:176-85.

5. The FO, Boeckxstaens GE, Snoek SA, et al. Activation of the cholinergic anti-inflammatory pathway ameliorates postoperative ileus in mice. Gastroenterology 2007;133:1219-28.

6. Eskandari MK, Kalff JC, Billiar TR, et al. LPS-induced muscularis macrophage nitric oxide suppresses rat jejunal circular muscle activity. Am J Physiol 1999;277:G478-86.

\section{Pathological lesions in colonic biopsies during Parkinson's}

\section{disease}

Parkinson's disease (PD) is a neurodegenerative condition that affects $1 \%$ of the population over 65 years of age. The two pathological hallmarks of PD are a loss of dopaminergic neurons in the substantia nigra (SN) and the presence of cytoplasmic eosinophilic inclusions termed Lewy bodies (LBs), whose main component is phosphorylated $\alpha$-synuclein. ${ }^{1}$ This degeneration of $\mathrm{SN}$ neurons leads to a dopamine deficiency 

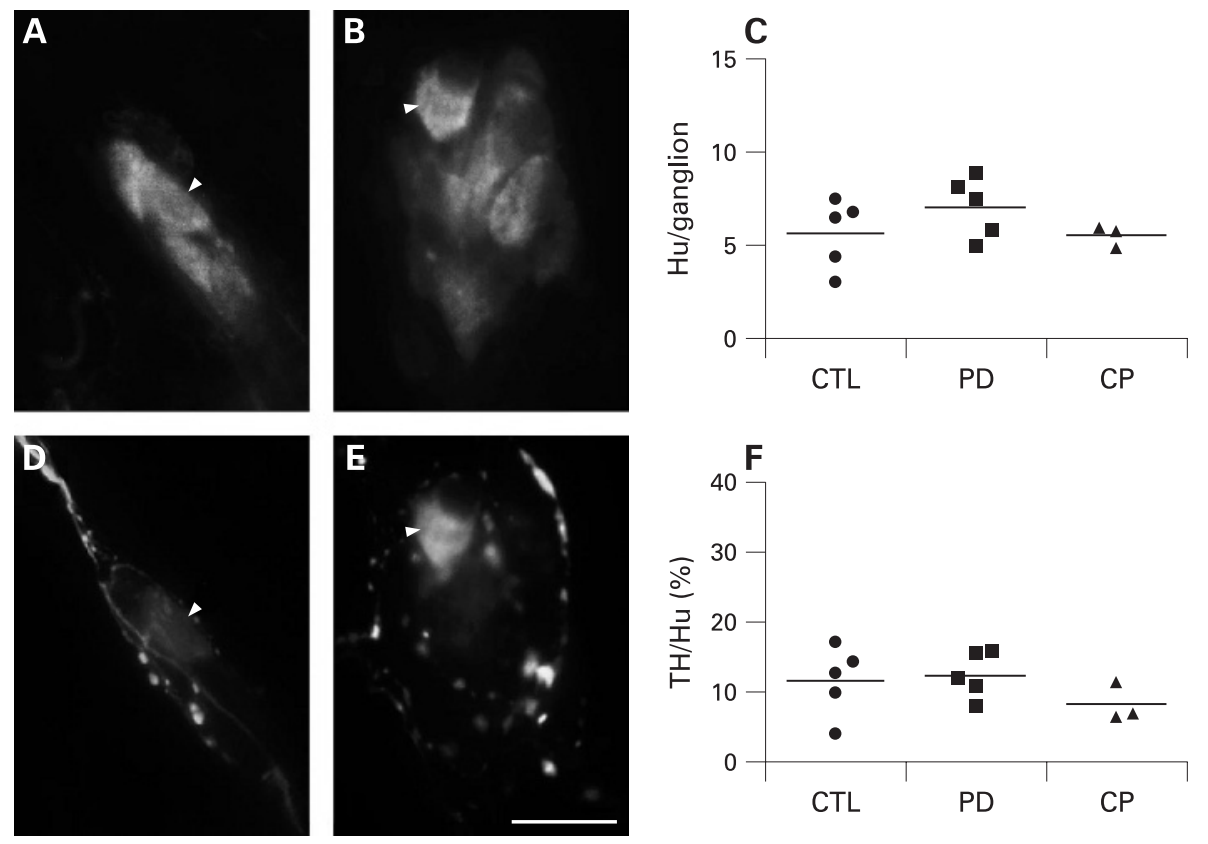

Figure 1 Submucosal neuron counts and dopaminergic phenotype are unchanged in patients with Parkinson's disease (PD). Hu-immunoreactive (IR) submucosal neurons were identified in the colon of controls $(n=5)(A), P D$ patients $(n=5)(B)$ and constipated patients $(n=3)$. There was no change in the number of Hu-IR submucosal neurons per ganglion in the three conditions (C). Double labelling with antibodies against $\mathrm{Hu}(\mathrm{A}, \mathrm{B})$ and tyrosine hydroxylase $(\mathrm{TH})(\mathrm{D}, \mathrm{E})$ showed that occasional submucosal neurons were TH-IR (arrow heads). No significant decrease in the proportion of TH-IR submucosal neurons occurred in PD and in constipated patients (F). Each circle, square and triangle represents one control, $\mathrm{PD}$ or constipated patient, respectively. Horizontal bars represent the mean. Scale bar: $20 \mu \mathrm{m}$. CTL, control; CP, constipated patient.

responsible for the major motor symptoms. Nevertheless, it has become increasingly evident that PD is a multicentric neurodegenerative process that also affects neuronal structures outside the $\mathrm{SN} .^{2}$ In this context, various reports performed on surgical or autopsy specimens have shown that the enteric nervous system (ENS) is affected during PD. ${ }^{3}$ However, it is still a matter of debate whether these alterations occur early in the course of the disease. This is mainly due to a lack of accessibility to the ENS in the living patients. Therefore, demonstrating (1) the ability to study the ENS using routine colonic biopsies and (2) the presence of lesions characteristics of PD could be relevant for an early diagnosis of the disease and to better understand its pathophysiology.

We therefore performed routine colonic biopsies in five $\mathrm{PD}$ patients complaining of functional constipation (63 (SD 7) years, three men; all had disease duration $>5$ years). Five healthy age-matched patients (61 (SD 6.5) years, one man) requiring a total colonoscopy for colorectal cancer screening were included as controls. They had no known neurological disease. None suffered from functional digestive symptoms. In order to avoid any specific role for chronic constipation, we included three additional non-agematched patients (52 (SD 5) years, no men) who underwent total colonoscopy for the assessment of a chronic intractable constipation as additional controls. Written consent was obtained according to the principles of the Declaration of Helsinki.

Four biopsies were taken from the ascending colon during colonoscopy. Biopsies were performed using standard biopsy forceps without needles (FB210K; Olympus, Tokyo, Japan). Samples were immediately immersed in $4^{\circ} \mathrm{C}$ saline solution and microdissected in order to separate the submucosa (containing the internal submucosal plexus) from the mucosa. The submucosa were then fixed in $4 \%$ paraformaldehyde. Imunohistochemical studies were then performed on these tissues using a combination of antibodies against rabbit antityrosine hydroxylase (TH) (1:500, Pel-Freez, Rogers, Arkansas, USA), rabbit anti-dopamine$\beta$-hydroxylase (DBH) (1:250, Millipore, SaintQuentin-en-Yvelines, France), mouse anti-Hu C/D (1:200, Invitrogen, Cergy-Pontoise, Fance), rabbit anti-phosphorylated $\alpha$-synuclein (1:5000, WAKO, Osaka, Japan) or rabbit antineurofilament $200 \mathrm{kDa}$ (1:250; Millipore) as previously described.

In control patients, individual biopsies contained 11.2 (SD 7.9) ganglia and each ganglia contained 5.6 (SD 1.9) Hu-immunoreactive (IR) neurons. In PD patients, the number of ganglia per biopsies was similar to controls (13.6 (SD 5.3); $p=0.22$ ). In addition, the number of $\mathrm{Hu}-\mathrm{IR}$ neurons per ganglion in $\mathrm{PD}$ was unchanged as compared to controls (7.0 (SD 1.6); $\mathrm{p}=0.25$ ) (fig
1A,C). Constipated controls did not differ from $\mathrm{PD}$ patients in the number of ganglia per biopsy (11.3 (SD 1.5); $p=0.57$ ) or in the number of neurons per ganglion (5.5 (SD 0.6); $\mathrm{p}=0.19)$ (fig 1C).

In healthy controls, 11.6 (SD 5.0 )\% of $\mathrm{Hu}-\mathrm{IR}$ neurons were TH-IR. In PD patients, the proportion of TH-IR neurons was unchanged as compared to controls (12.3 (SD 3.3)\%; p =0.80) (fig 1D-F). In constipated patients, the proportion of TH-IR neurons was similar to the one of $\mathrm{PD}$ patients (8. (SD 2.7)\%; $\mathrm{p}=0.12$ ) (fig $1 \mathrm{~F}$ ). In all groups no neuronal body was $\mathrm{DBH}$ positive, suggesting that all $\mathrm{TH}$ IR neurons in the submucosal plexus were dopaminergic. These results are consistent with a previous report by Singaram et $a l^{6}$ showing the absence of loss of TH-IR neurons in the submucosal and myenteric plexuses of PD patients, suggesting that it is not a marker of choice for detecting $\mathrm{PD}$ lesions in the ENS.

However, immunohistochemical staining with an antibody against phosphorylated $\alpha$-synuclein, revealed that 4 out of 5 PD patients had phospho- $\alpha$-synuclein-IR neurites (identified with neurofilament (NF) in the submucosa (fig 2A,F). These phospho$\alpha$-synuclein-IR neurites were absent in both control and constipated patients. In some cases, large aggregates were observed in dystrophic NF-IR neurites (fig 2E), a pattern reminiscent of Lewy neurites.

Taken together, our pilot study showed that routine colonic biopsies can be used to study the submucosal plexus of the ENS. In addition, we identified for the first time in the gut of living PD patients lesions similar to the ones observed in the brain. This technique could be a reliable tool to detect early lesions in the gut during the course of $\mathrm{PD}$ in order to better understand the pathogenesis of the disease and/or to identify novel biomarkers.

T Lebouvier, ${ }^{1,2,3,4}$ T Chaumette, ${ }^{1,2,3}$ P Damier, ${ }^{2,4,5}$ E Coron, ${ }^{1,2,3,5}$ Y Touchefeu, ${ }^{1,2,3}$ S Vrignaud, ${ }^{6}$

P Naveilhan, ${ }^{2,7}$ J-P Galmiche, ${ }^{1,2,3,5}$

S Bruley des Varannes, ${ }^{1,2,3,5}$ P Derkinderen, ${ }^{1,2,3,4,5}$ M Neunlist ${ }^{1,2,3,4}$

${ }^{1}$ Inserm, U913, Nantes, France; ${ }^{2}$ University Nantes, Nantes, France; ${ }^{3} \mathrm{CHU}$ Nantes, Institut des Maladies de I'Appareil Digestif, Nantes, France; ${ }^{4} \mathrm{CHU}$ Nantes, Department of Neurology, Nantes, France; ${ }^{5}$ Inserm, CIC-04, Nantes, France; ${ }^{6} \mathrm{CHU}$ Nantes, Department of Anesthesia, Nantes, France; ${ }^{7}$ Inserm, U643, Nantes, France

Correspondence to: Dr M Neunlist, Inserm U913, 1 place Alexis Ricordeau, 44093 Nantes, France; michel.neunlist@ univ-nantes.fr or Dr P Derkinderen, Department of Neurology, CHU Nantes, 44093 Nantes, France; pascal.derkinderen@ chu-nantes.fr

Acknowledgements: The authors wish to thank M Roy and $F$ Vavasseur for their help in the assessment of patients and controls.

Funding: This work was supported by a grant from France Parkinson, ADPLA (association des parkinsoniens de Loire Atlantique), Groupement de Parkinsoniens de Vendée and Inserm/DHOS (to PDe and MN). PDe and MN are recipients of a Contrat d'Interface Inserm.

Competing interests: None. 

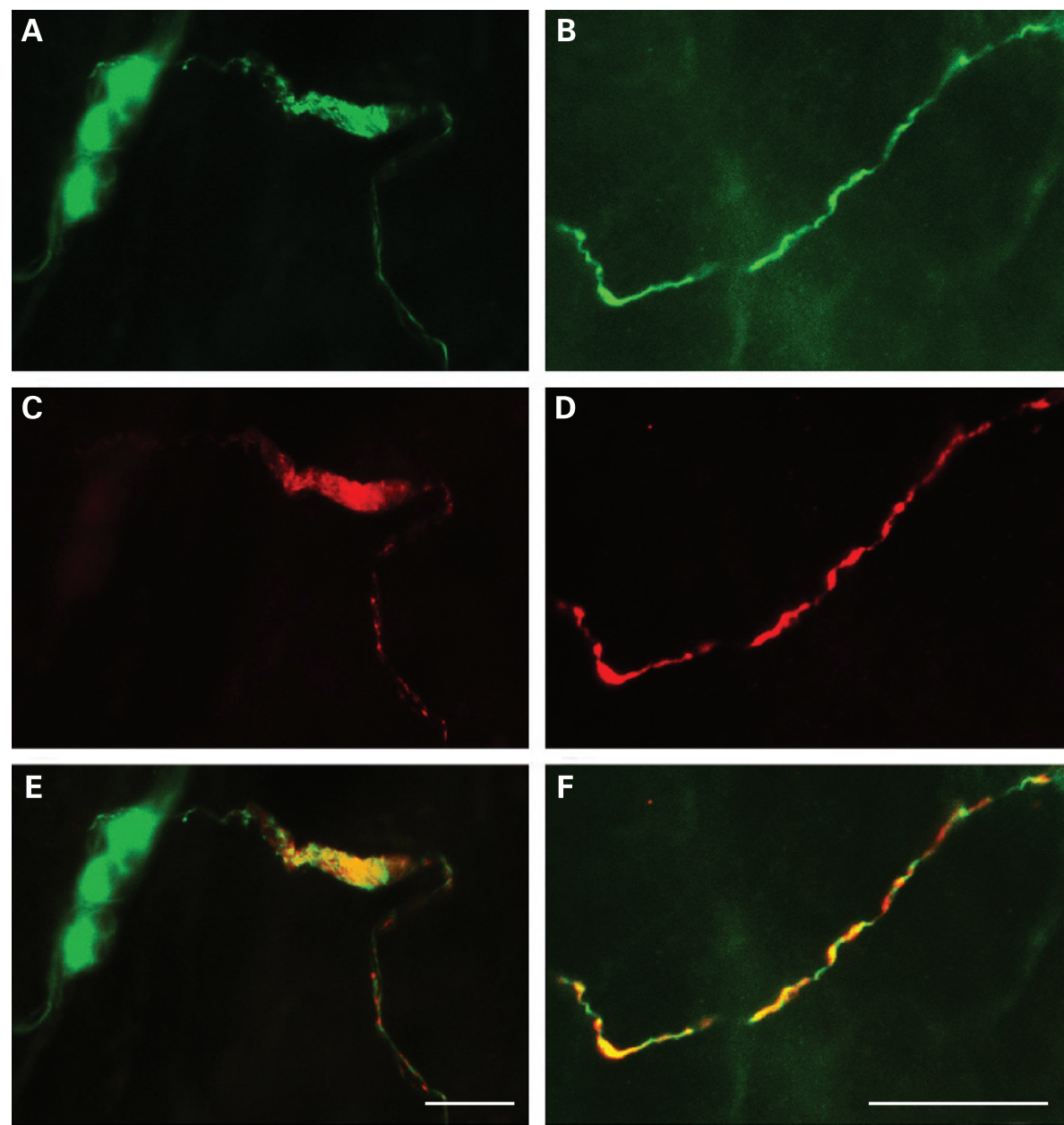

Figure 2 Phospho- $\alpha$-synuclein-positive submucosal neurites differentiate Parkinson's disease patients from controls. Double labelling with antibodies against neurofilament (NF) $(A, B)$ and phosphorylated $\alpha$-synuclein $(\mathrm{C}, \mathrm{D})$ revealed that some NF-immunoreactive (IR) neuritic structures were also phospho- $\alpha$-synuclein-IR (merged image in $E, F$ ) in the majority of Parkinson's disease patients, but in none of the controls. Occasionally the inclusion-bearing neurites displayed dystrophic alterations $(A, C, E)$. Scale bar: $30 \mu \mathrm{m}$.
Ethics approval: The study protocol was approved by the local Committee on Ethics and Human Research on 27 February 2007.

TC and TL as well as PD and MN contributed equally to this work.

Gut 2008;57:1741-1743. doi:10.1136/gut.2008.162503

\section{REFERENCES}

1. Fujiwara H, Hasegawa $\mathrm{M}$, Dohmae $\mathrm{N}$, et al. asynuclein is phosphorylated in synucleinopathy lesions. Nat Cell Biol 2002;4:160-4.

2. Braak H, Del Tredici K. Nervous system pathology in sporadic Parkinson disease. Neurology 2008; 13;70:1916-25.

3. Braak H, de Vos RA, Bohl J, et al. Gastric alphasynuclein immunoreactive inclusions in Meissner's and Auerbach's plexuses in cases staged for Parkinson's disease-related brain pathology. Neurosci Lett 2006;396:67-72.

4. Wakabayashi K, Takahashi H, Takeda S, et al. Parkinson's disease: the presence of Lewy bodies in Auerbach's and Meissner's plexuses. Acta Neuropathol 1988;76:217-21.

5. Neunlist M, Aubert P, Toquet C, et al. Changes in chemical coding of myenteric neurones in ulcerative colitis. Gut 2003:52:84-90.

6. Singaram C, Ashraf W, Gaumnitz EA, et al. Dopaminergic defect of enteric nervous system in Parkinson's disease patients with chronic constipation. Lancet 1995;346:861-4.

\section{CORRECTION}

doi:10.1136/gut.2007.119446corr1

R Spiller, O Aziz, F Creed, et al. Guidelines on the irritable bowel syndrome: mechanisms and practical management (Gut 2007;56:1770-98). In paragraph 4.4.1 the sentence "This in turn acts on the adrenal medulla, resulting in cortisol secretion into the circulation" should read "This in turn acts on the adrenal cortex, resulting in cortisol secretion into the circulation".

\section{Editor's quiz: GI snapshot}

\section{ANSWER}

From the question on page 1673

The patient had a large inflammatory abdominal aortic aneurysm. The abdominal CT scan shows a large infrarenal aortic aneurysm with a maximum diameter of $7.5 \mathrm{~cm}$ extending into the iliac vessels. There is an enhancing soft-tissue cuff surrounding the anterolateral margin of the aneurysm. The aneurysm appears to compress the third part of the duodenum (fig 1 below), which, however, was not detected at endoscopy. These CT findings were suggestive of an inflammatory aneurysm. Inflammatory abdominal aortic aneurysms represent $3-10 \%$ of all abdominal aortic aneurysms and occur predominantly in men. ${ }^{1}$ They differ from atherosclerotic aneurysms in that patients often present with abdominal symptoms or anorexia, weight loss, and raised inflammatory markers. CT has a specificity of $99.7 \%$ for diagnosis of inflammatory aneurysms, ${ }^{2}$ usually showing periaortic fibrosis as a cuff of enhancing soft tissue surrounding the anterolateral margin of the aneurysm. If periaortic fibrosis is extensive, adjacent abdominal structures may be compressed and adherent, most commonly the third part of the duodenum. ${ }^{1}$ Although rare, inflammatory abdominal aortic aneurysms should be kept in mind as a cause of abdominal pain and/or anorexia, weight loss, and raised inflammatory markers. The natural history of inflammatory abdominal aortic aneurysms remains unknown, with $3.3-14 \%$ patients presenting with acute or chronic rupture. ${ }^{1}$ As regards to management, the literature supports an operative approach with a 30 day operative mortality rate of up to $9 \%{ }^{1}$ Complete regression of fibrosis and inflammatory process occurs in up to one-half of patients at long-term follow-up postoperatively. Clinical symptoms (such as weight loss and gastrointestinal symptoms) reverse in $93 \%$ of the patients after an operation. ${ }^{3}$ Endovascular therapy is also a potential treatment 